\title{
Dynamic Formation Of Autonomus Agents Based On Algorithm Flocking Behavior
}

\author{
Mursyidah $^{1}$, Ahmad Ihsan $^{2}$ and Atthariq ${ }^{1}$ \\ \{mursyidah@pnl.ac.id,ahmadihsan@unsam.ac.id, atthariq@pnl.ac.id\} \\ ${ }^{1}$ Departement of Information Technology and Computers, Politeknik Negeri Lokseumawe,Indonesia \\ ${ }^{2}$ Departement of Information Technology and Computers, Universitas Samudera, Indonesia
}

\begin{abstract}
Approach to organizing group formations still are static, causingthe formation has not been able to adapt to the changing circumstances of both obstacle or barrier that will be encountered.This study was to model the behavior of autonomous agents formation dynamic moves past the obstacles and reshaping the initial lineup after passing obstacles based algorithm flocking behavior. There were four formations that are examined in this study i.e. column formation, a circle, a line formation and the formation of the triangle. All forms of word formation in narrow spaces and one labyrinth. The labyrinthine 121, 123 and labyrinth mazes is structuring three zigzag number of narrow spaces is bypassed by the formation of autonomous agents. The results of the error of the average position of the formation of autonomous agents in one narrow space is $0 \%$. At 121 maze, the percentage error of the position of the movement of the formation is the largest circle formation agents namely $52.63 \%$ and the percentage error of the triangular formation is the smallest position i.e. $44.83 \%$. In the maze of 123 , the percentage error of the triangular formation is the largest position i.e. $55.42 \%$ and the smallest is the position error percentage column namely $42.42 \%$. The percentage error of the position of the movement of the formation of the largest agencies in the maze of zigzag formation is the circle i.e. $90.69 \%$ and the smallest is the position error percentage column namely $48.488 \%$.
\end{abstract}

Keywords: Dynamic, Formation Flocking behavior, past obstacles.

\section{INTRODUCTION}

Modeling and simulation of flocking get special attention in the field of multimedia and entertainment industry, especially in the production of commercials and movies. Flocking done animation of automation to reduce process and production costs. Group formation is a formation that is widely used to simulate large battle scenes in games and films such as realtime strategy like a Total War, and blockbuster, a movie like Avatar and The Lord of The Ring. The formation of the group becoming a challenge for researchers because it requires an efficient algorithm to handle a bunch of characters while maintaining the form formation and autonomy among groups. 
Reynold [1], one of the researchers who introduced the model the behavior of a group of birds, animals and fish, concluded that the behavior of the group can be decomposed into several steering behavior is simple on the level of the individual, with concentrate on the coordination between local agents. Set steering behavior modeled based on physical parameters including mass, speed, position and orientation [1].

Steering behavior represents the movement of autonomous agent behavior of a virtual world. There are some simple behavior at steering the individualagents to drive agents namely seek, flee, budget, obstacle avoidance, leader following and flocking behavior.

On the research of Flocking for dynamic multi-agent systems: Algorithms and theory [2], explains the link between theory and algorithms in the field of flocking and dynamic multiagent system. There are some fundamental questions of flocking and dynamic multi-agent system: 1 . How to make a stability system that can keep the movement of a large number of agents on the frame-rate of $30 \mathrm{fps}$ ? 2 . How to control the formation of agents that can maintain a specific formation? 3. how the formations agent avoid collisions and avoid obstacles by static and dynamic obstacles?

The behavior of flocking agents NPCS (non-player character) is implemented in the form of many top lines. The formation can be defined as a group of units with a specific purpose, are positioned to form a pattern or certain shape and applied to the destination pattern of assaults or as tactical defense. Approach to organizing group formations are usually still purely static. Static formations still hasn't been able to adapt to the changes of obstacles or obstructions.

On the research of the change movement formations of troops with fixed geometry pattern using the boids [3], discusses the State of the conduct of troops in formation that positioned in one specific point to form a specific pattern ordered by the leader and avoid a collision with fellow agent average speed. The shape of the formation can be a parallel line pattern, the shape of "V", column, circle and others. The form of this formation has a sense of history and is still used in modern military operations.

Formation in organizing groups usually still purely static. Static formations have not been able to adapt to changes in the barrier or obstacle faced by the Agency. To overcome the problem of static formations, then required the formation of a dynamic nature has the ability to pass through a narrow space with obstacles entering a predetermined path and was able to avoid a collision between agents. At the time of the formation of a narrow room facing agents, each agent automatically detach from the formation as well as continue to move past the narrow space, and then regroup into formations early after going through the obstacles and reshape the formation early and avoid the collision of fellow agent-based algorithm of flocking behavior.

\section{LITERATURE REVIEW}

The movement of the Group was first popularized by Craig w. Reynolds circa 1986, by making a model of computer animation in the form of coordinated animal motion, which is an imitation of the real world that is the motion of troop of birds. Of these groups of animals can be observed, every bird that is in that group have a behavior that makes it possible to coordinate the movement against friends who became his closest neighbors. The natural shape of the groups affected by the balance of contention two behaviors i.e. desire remains close to 
his group (cohesion) and the desirability of avoiding collision between the Coulomb (collision avoidance).

The impetus for the Group (flocking) is usually influenced by the State of the environment in the vicinity, such as protection from predators (predator). In addition, birds can also avoid crowding each other between each other, so that if there is the addition of new members, the group does not become full or excess (separation). The last thing, every Member of the birds move with the speed of an average against his group and headed towards the same goal (aligment). From these conditions, to form a movement of a group of animation, Craig w. Reynolds made a rule, model bird modelled into a boid. Boid then given a wheel to be able to move, this is called steering steering behaviour and is most often used to boids is separation, cohesion and aligment. Steering behaviour this is a point of discussion on the topic of weight of this chapter. But before discussing such things, there are some basic theory to develop steering behaviour.

\subsection{Formation}

Its formation is defined as a unit setting or disposition. The formation is usually applied to tactical, objective and have been found in tribal societies such as Maori. The formations often look like a wall of shields, or wedge, which has historically and are still used in modern military [4].
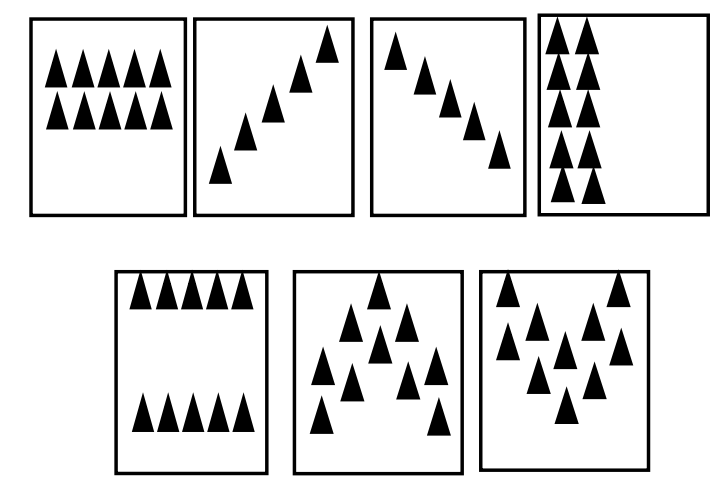

Fig. 1 Shape - the shape of the formation. (a) the form of the line formation, (b) the form of leftwing formations, (c) the form of the right-wing formations, (d) the form of a column, (e) the form of a box formation, (f) the shape of the wedge formation $(\mathrm{g})$ Shape the formation of $\mathrm{V}$ The formation is widely used in a variety of games, ranging from real-time strategy games to sports games. The formation became the flagship strategy to confront the enemy. There are several forms of formation that usually has a value of history in military operations, examples of the form formation can be seen in Figure 1.

\subsection{Autonomous Intelligent Agent}

Autonomy and intelligence agent, is the idea that everything is difficult to define. Agents are closely linked with the nature of the agent such as autonomy, situatedness and embodiment.

- Autonomy

The Agent has a mechanism that allows the agent to sense the environment and act upon it and does not require the intervention of another agent to executed. 
Franklin and Graesser [5]defines: "autonomous agent is a system that is located within the neighborhood and is part of the environment as well as able to sense the environment and act on it." All the agent software is a computer program, but not all programs are the agents.

\section{- Situatedness}

Situatedness is the existence of the system in an environment as well as the interaction of the system with its surroundings is considered implicit properties of agents [6].

\section{-Embodiment}

Embodiment is a very important trait for autonomous agents. Embodiment is the nature of the agent which refers to property agents to have a body shape that can interact with the surrounding environment. This asset is important for agent capability. Usually refers to objects, such as animals or robots. Some quick research. Some quick research, Dautenhahn and Coles [7], argue that embodiment is not necessarily given by the materialitasnya, but a dynamic relationship with the environment and actions that may affect the environment. Realization can also occur in an environment other than the material world, such as computing. The environment can be simulated, or a truly computational physical environment, such as the Internet or the operating system.

\section{- Intelligence}

Intelligence is the ability of agents to learn from experience, to adapt to the new situation and changes in the environment, or to continue to think in the abstract. The MIT encyclopedia of the Cognitive Sciences States: intelligent agent is a device that interacts with its environment in a flexible, ways to achieve goals, recognize the importance of the environment and the circumstances of the Act to achieve the results desired [6].

Figure 2 provides a simple overview about the behavior of agents to the environment, which shows that the output action posed by such agents can affect the environment. In a complex environment that agents could not do full control (complete control) to the environment. That can be done by the agent is partial control (control per part) and this can affect the environment. An agent is something that can sense the environment through the sensor and give action to the environment through the effecto

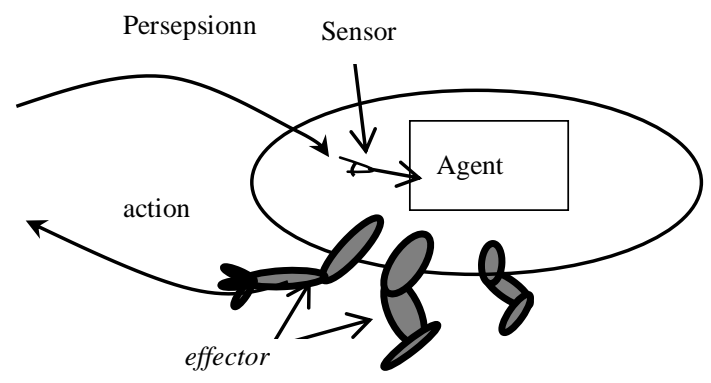

- Separation

Fig. 2 Agents in their surroundings[8]

Separation is one of the rules of conduct group agents who used to be able to keep distance between agents aiming to avoid a collision with its neighbors. Separation behavior also often referred to as collision avoidance steering Behavior i.e. to prevent collision between agents. Separation is the speed of decline (myrna I, 2011). Figure 3 shows that only the 
neighboring Agent $\mathrm{n}$ within a radius of Rsep being evaluated. A vector $\mathrm{v}$ is the speed of the wheel resulting. Equations of Separation:

$$
\text { Separation }=\frac{1}{M} \sum_{n=1}^{M} \frac{(P i-p n)}{d(p i-p n)}
$$

where ' $M$ ' is the number of agents from a distance of a minimum of agent ' $\mathrm{i}$ ', pi is the position of agent ' $\mathrm{i}$ ', and d (pi, pn) is the distance between the agent and the agent neighbors 'i' n'.

Speed separation agent $i$ is the linear combination of the unit vector in the direction of the nearest neighbors. Thus, each agent neighbors give the same influence on the agent ' $i$ ', with only a change of direction.

The speed of separation of ditunjaukkan in Figure 3 where ' $R$ ' is the outer circle of the Environment Agency, the inner circle of Rsep is the distance of separation, Separation of the environment direct the agent ' $\mathrm{i}$ ' avoid/approaching the neighbor ' $\mathrm{n}$ ' until the minimum distance between the agent and the neighbor ' $n$ ' $i$ ' fulfilled [9].

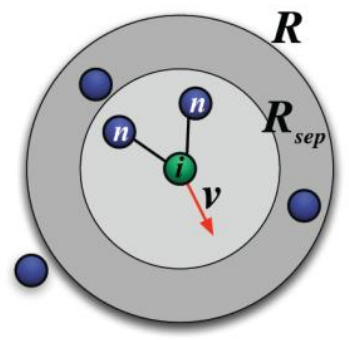

Fig. 3 The speed of separation

\section{- Alignment}

Harmony is a group of agents with rules of conduct each agent with a neighboring speed velocity aligning. Alignment behavior also often called velocity matching [9]. Figure 4 shows the alignment speed to match the speed and position of agent ' $i$ ' with neighboring ' $n$ '. speed Steering behavior is calculated using equation 2 .

$$
\text { Alignment }=\left[\frac{1}{N} \sum_{n=1}^{N} v_{n}\right]-v_{i}
$$

where ' $\mathrm{N}$ ' is the number of agents in the radius $\mathrm{R}$ centered on the agent ' $\mathrm{i}$ ' $(\mathrm{R}>\mathrm{Rsep})$. " $\mathrm{vn}$ " is the speed of the neighboring ' $n$ '. Speed Alignment direction vector is a corrective to the desired speed, which is also the center of mass.

The speed of the alignment figure 4, the circle R is the Environment Agency ' $\mathrm{i}$ ', vector "vi" working on agent ' $\mathrm{i}$ ' is the desired speed, keselaransan match the position and speed of agent i' with neighboring speed 'n' [9].

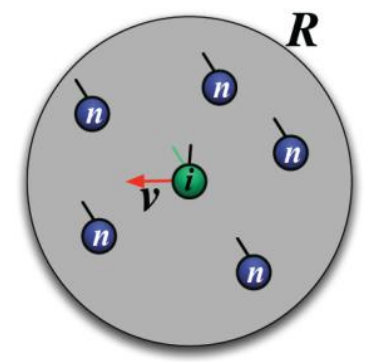

Fig. 4 Speed alignment 


\section{- Coheson}

Cohesion is used to redirect the Agency toward the center of the swarm. The behavior of cohesion also often called flock, as the concentration of efforts in order that the Agency remains close to its neighbors. The formula that is used for cohesion is very similar to the formula that is used for the alignment. The difference is temporary agent positions using cohesion alignment using the speed agents [9]. Figure 5 illustrates the speed of cohesion that directs the agent 'I' toward the center of the neighborhood.

$$
\text { Cohesion }=\left[\frac{1}{\mathrm{~N}} \sum_{\mathrm{n}=1}^{\mathrm{N}} \mathrm{p}_{\mathrm{n}}\right]-\mathrm{p}_{\mathrm{i}}
$$

where ' $\mathrm{N}$ ' is the number of agents in the local environment boid ' $\mathrm{I}$ ', and ' $\mathrm{n}$ ' is the position of the neighboring "pn". The direction of movement to the agent ' $i$ ' was headed for the center of mass of the agent in the local environment.

The speed of cohesion figure 5. the circle ' $R$ ' is the Environment Agency ' $i$ ', cohesion directs agents to their local environment ' $i$ ' [9].

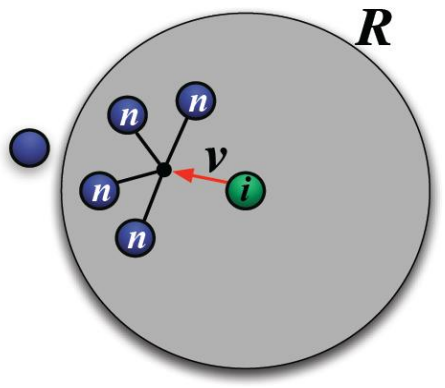

Fig. 5 The speed of cohesion

- Goal

The target is the behavior that can attract agents to specific locations in the global space. This location is static. Figure 6 shows the actions taken when approaching the target. Vector $v$ shows the direction taken by the agent towards the goals. Vectors vi is the desired speed, while the dotted line is the actual path taken by the agent.

The behavior of the Target will adjust the speed of the dealer in a way that is aligned towards the target. Because the target is static, the equation (2.4) is used to calculate the desired speed that is a unit vector (from the agent to the target) and set the desired speed with the magnitude of the maximum speed allowed (maxspeed) to approach the target as soon as possible [9].

$$
\text { Goal }=\left[\frac{\left(p_{t}-p_{i}\right)}{d\left(p_{t}, p_{i}\right)} * \max _{\text {speed }}\right]-v_{i}
$$

with "pi" and "vi" are the position and velocity of agent ' $\mathrm{i}$ ', and "pt" is the position of the target. So agents will approach the goal

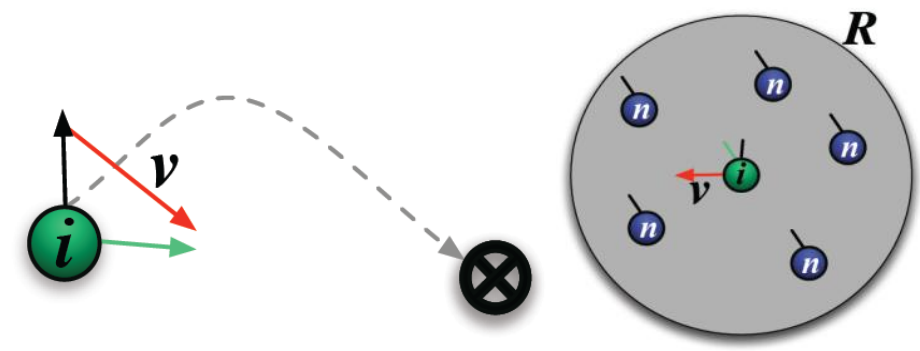

Fig. 6 : Target behavior: agent $i$ approaches the target when it concerns the behavior of the Goal[9] 


\section{- Evasion (avoid)}

Avoidance or avoid referring to wheel away from the static target agent in global space. This approach is the opposite of steering target. The desired speed avoid points in the opposite direction of the speed of the desired goals [9].

Figure 7, illustrates the Steering vector with the 'v' and the desired speed in the "vi". so, avoid the formula becomes: $-\mathrm{v}_{\mathrm{i}}$.

$$
\text { Evasion }=-\left[\frac{\left(\mathrm{p}_{\mathrm{t}}-\mathrm{p}_{\mathrm{i}}\right)}{\mathrm{d}\left(\mathrm{p}_{\mathrm{t}} \mathrm{p}_{\mathrm{i}}\right)} * \max _{\text {speed }}\right]
$$

The negative sign indicates that the point it towards the opposite direction with speed towards the goal.

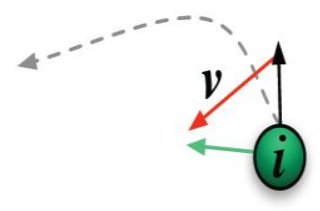

Fig. 7 Agent avoid Conduct ' $i$ ' move away from the target when subjected to behavioral avoidance[9]

\section{- Leader Following}

Leader following is behavior which characters follow one leader. If a leader has been marked then the character of the followers will follow the leader. The followers are generally located close to the leader but not clustered with the leader. If there is more than one follower, they are going to avoid collisions with each other. To implement this behavior use behavior is a budget and separation. The behavior of the function is a budget to keep up with the leaders so that the motion of the characters do not go beyond the leader.

Whereas the purpose of keep not clustered with other characters [9]. Figure 8 shows the behavior follow the leader with agents follower " $n$ " follow the leader ' $i$ '.

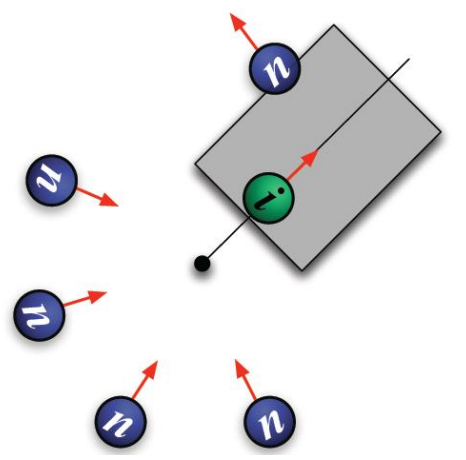

Fig. 8 follow the leader Behavior: Agent follower 'n' follow 'i' with leaders approached the leader[9]

\section{METHODS}

\subsection{Formation Of Autonomous Agent Design}

To move towards the target, any agent of the follower are designed following the agents leader as see. Each autonomous agent dynamic moves against the obstacles that have been determined. 


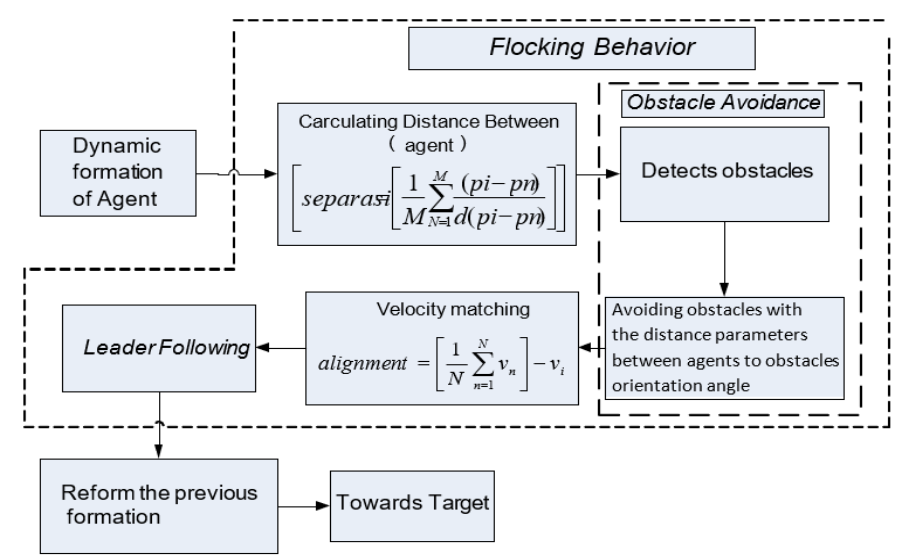

Fig. 9 Block Design Research

\subsection{Desain Algoritma Flocking Behavior}

Figure 10. shows the flowchart algorithms flockingbehavior formation of autonomous agents that used to pass through a narrow space and reshaping the initial formation.

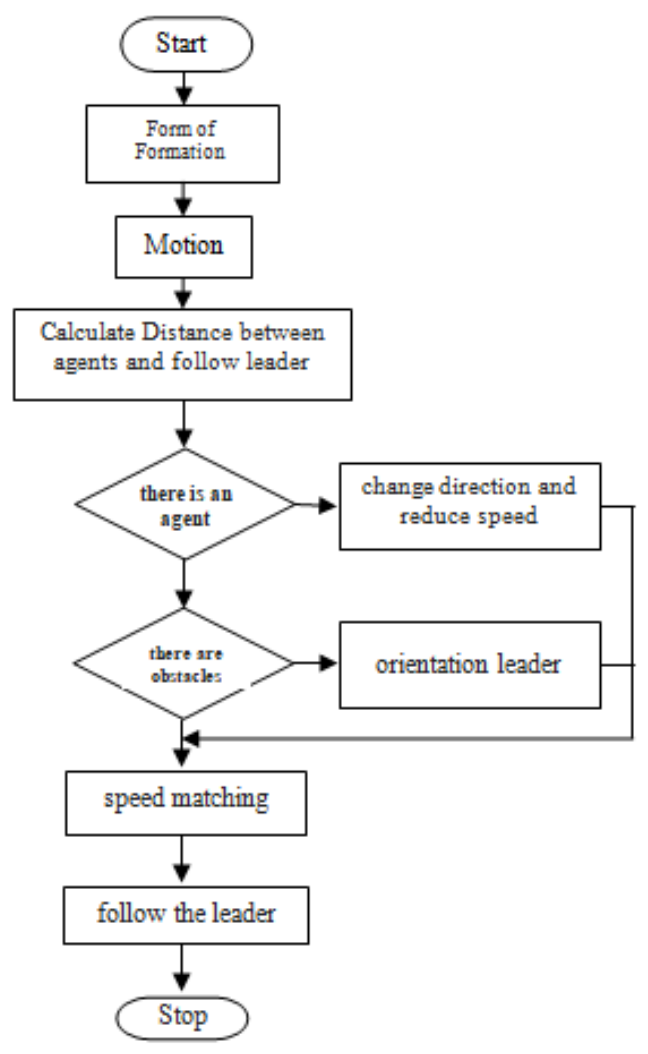

Fig. 10 Flowchart Algorithms Flocking Behavior 


\section{RESULT AND DISCUSSION}

To evaluate the performance results from this research, used 30 agents in each formation. The formation tested against the obstacle is the formation of the line, column, circle and triangle. Any formation of autonomous agent moves to the target and passes through the obstacles that have been specified. The hurdles that must be crossed by the agent in the form of a narrow space the length of 28 meters and a simple maze. The maze is static obstacles impassable formation agent. The shape of the maze which bypassed the formation is a maze of 121,123 and labyrinthine maze of zigzag. The labyrinthine 121, 123 and labyrinth mazes is structuring three zigzag number of narrow spaces is bypassed by the formation of autonomous agents. The movement of the watch at the time of an agent in the agent passes through a narrow space and movement of the formation of initial formation agent after passing through a narrow space.

At the moment will enter the narrow space, the distance of the agents in the count against the obstacle, the angle of the orientation of the agent, agent in need of time to go through the obstacles and the time needed to establish the initial formation of the agents as well as agents of the position after the error percentage passing through narrow space which is a parameter of the study. In testing, statistical calculations done 10 times simulations for each form formations are shown in table 1.

When passing trough the obstacles in the count at the time the agent moves until all agents have already made it through the obstacles. Time needed for formation early in the count at the time the agent moves until every agency was already in the initial positionand formed the original lineup.The percentage of error position is calculated by counting the number of agents that are not right in his position in for with the amount of agent in multiply $100 \%$.

Table 1. The movement of formation of Agent passing through narrow space

\begin{tabular}{ccccccccc}
\hline \multicolumn{7}{c}{ Movement Formation agent on labyrinth 121} & \multicolumn{3}{c}{ Movement Formation agent on labyrinth 123} \\
\hline & $\begin{array}{c}\text { Column } \\
\text { formation }\end{array}$ & $\begin{array}{c}\text { Oval } \\
\text { formation }\end{array}$ & $\begin{array}{c}\text { Line } \\
\text { formation }\end{array}$ & $\begin{array}{c}\text { Triangle } \\
\text { formation }\end{array}$ & $\begin{array}{c}\text { Column } \\
\text { formation }\end{array}$ & $\begin{array}{c}\text { Oval } \\
\text { formation }\end{array}$ & $\begin{array}{c}\text { Line } \\
\text { formation }\end{array}$ & $\begin{array}{c}\text { Triangle } \\
\text { formation }\end{array}$ \\
\hline $\begin{array}{c}\text { Time } \\
\text { passes } \\
\text { through } \\
\text { obstacles }\end{array}$ & 47.56 & 35.20 & 43.94 & 46.75 & 43.189 & 35.20 & 43.94 & 49.088 \\
$\begin{array}{c}\text { Formation } \\
\text { time of } \\
\text { initial } \\
\text { formation } \\
\begin{array}{c}\text { Percentage } \\
\text { of position } \\
\text { error }\end{array}\end{array}$ & 149.41 & 145.07 & 148.5 & 159.72 & 162.46 & 157.19 & 153.50 & 161.91 \\
\hline
\end{tabular}


Table 2. The movement of agent formation passes through the labyrinth 121 and 123

\begin{tabular}{cccc}
\hline $\begin{array}{c}\text { Type } \\
\text { Formation }\end{array}$ & $\begin{array}{c}\text { Time passes } \\
\text { through } \\
\text { obstacles } \\
\text { (seconds) }\end{array}$ & $\begin{array}{c}\text { Formation time } \\
\text { of start time } \\
\text { (seconds) }\end{array}$ & $\begin{array}{c}\text { Percentage Error } \\
\text { position of autonomous } \\
\text { agent }\end{array}$ \\
\hline Column & 43.066 & 83.214 & 0 \\
Oval & 36.74 & 76.24 & 0 \\
Line & 43.039 & 98.603 & 0 \\
Triangle & 51.86 & 88.93 & 0 \\
\hline
\end{tabular}

Table 3. The movement of formations in the maze of zigzag

\begin{tabular}{ccc}
\hline $\begin{array}{c}\text { Type } \\
\text { Formation }\end{array}$ & $\begin{array}{c}\text { Formation time of start time } \\
\text { (seconds) }\end{array}$ & $\begin{array}{c}\text { Percentage Error position of } \\
\text { autonomous agent }(\%)\end{array}$ \\
\hline column & 200.881 & 48.488 \\
oval & 304.641 & 90.67 \\
line & 225.93 & 54.67 \\
triangle & 211.691 & 65.431 \\
\hline
\end{tabular}

\section{Conclusion}

Based on the trial results and the analysis of the results for the four agents of the autonomic formation using an algorithm flocking behavior on one narrow spaces and maze with three narrow amount of space Setup, formation of autonomous agents can reshape the initial formation but there is the agent could not get through obstacles by the amount of error is the average position of the formation of autonomous agents that can not pass through obstacles to $46.49 \%$ column formations, formations, formations, $65.77 \%$ Circle line $49.88 \%$ and $55.22 \%$ triangle formation. The large amount of error is the average position of the formation of autonomous agents can be caused by not yet optimal avoidance technique when the agent passes through obstacles or its complexity is caused by the narrow space Setup. The more narrow spatial complexity that bypassed the agent then the greater the error position formation of autonomous agents.

For the study, recommended can do optimization of movement of autonomous agents in the formation of the maze so that the percentage of error smaller positions.

\section{REFERENCES}

[1] C. W. Reynolds, "Steering behaviors for autonomous characters," Game Dev. Conf., pp. 763-782, 1999. 
[2] R. Olfati-Saber, "Flocking for Multi-Agent Dynamic Systems:Algorithms and Theory," IEEE Trans. Automat. Contr., vol. 51, no. 3, pp. 1-20, 2006.

[3] F. A. P, S. M. S. N, and M. Hariadi, "Perubahan Gerakan Formasi Pasukan Dengan Pola Tetap Geometri Berbasis Boids," vol. 11, no. 2, pp. 1-5, 2013.

[4] P. Tozour, "The Evolution of Game AI," Ai Game Program. Wisdom, vol. 1, pp. 3-15, 2002.

[5] S. Franklin and A. Graesser, "Is It an agent, or just a program?: A taxonomy for autonomous agents," pp. 21-35, 1997.

[6] R. V. Florian, "Autonomous artificial intelligent agents," Cent. Cogn. Neural Stud. Tech. Rep., 2003.

[7] Kerstin Dautenhahn and Steven J. Coles, "Narrative Intelligence from the Bottom Up:InA Computational Framework for the Study of Story-Telling in Autonomous Agents," no. 2001, pp. 1-15, 2016.

[8] P. Russel, Stuart; Norvey, Artificial intelligence: a modern approach. 2009.

[9] M. S. myrna I, "Flocking Implementation for the Blender Game Engine,"

Diginole.Lib.Fsu.Edu, 2011. 